\title{
Jogos Educacionais Digitais no Ensino Infantil: Uma Revisão Sistemática da Literatura
}

Lucineide Cruz Araújo - PPgITE-IMD-UFRN - neidinha.araujo@hotmail.com Charles Andryê Galvão Madeira - PPgITE-IMD-UFRN - charles@imd.ufrn.br

Resumo. As crianças estão imersas na cultura digital. Mesmo antes de frequentarem a escola, fazem uso de aparatos tecnológicos com interfaces de interação sensíveis ao toque, como é o caso dos jogos digitais, muitas vezes sem mediação. Este artigo tem por objetivo investigar trabalhos que analisam como os jogos educacionais digitais estão contribuindo no processo de ensino e aprendizagem das crianças da Educação Infantil. Para isso propõe uma revisão sistemática da literatura. Como resultado, verificou-se que os trabalhos analisados destacam o uso dos jogos digitais como uma importante ferramenta para a prática pedagógica e para a aprendizagem da criança, embora ainda existam lacunas de investigações no que se refere à relação dos jogos digitais com os campos de experiência citados pela BNCC, de forma que possibilite o desenvolvimento de habilidades.

Palavras-chaves: Educação Infantil, Jogos Educacionais Digitais, Processo de Aprendizagem.

\section{Digital Educational Games in the Kindergarten: A Systematic Literature Review}

Abstract. Children are immersed in the digital culture. Even before attending school, they generally use technological devices with touch interaction interfaces such as digital games, often without mediation. This paper aims to investigate works that analyze how digital educational games have contributed to the children's learning process in the kindergarten. For this reason, it proposes a systematic literature review. As a result, it has found that works analyzed highlighted the use of digital games as an important tool for pedagogical practice and for children's learning, although there are still research gaps regarding the association of digital games with the experience fields cited by the BNCC, in a such way that allows the skills development.

Keywords: Kindergarten, Digital Educational Games, Learning Process.

\section{Introdução}

Nos dias atuais, as crianças estão imersas em um mundo tecnológico, entram em contato com dispositivos eletrônicos logo na primeira infância, transformando sua realidade social e escolar. Apesar do crescente uso de softwares educativos no Ensino Básico, sua utilização no contexto da Educação Infantil ainda tem sido um desafio (Santana e Santos, 2018). Atentos à necessidade de inovar a fim de melhorar a qualidade do processo de ensino e aprendizagem, pensando nessa infância contemporânea que vem passando por transformações durante seu processo de constituição, muitos educadores estão buscando colocar em prática novas metodologias e instrumentos que possibilitem uma aprendizagem mais significativa (Gomes et al., 2015). Sendo assim, estudos recentes, especialmente com aporte teórico da sociologia da infância, têm sugerido pensar nas crianças pequenas enquanto protagonistas das práticas sociais, que interpretam e ressignificam a cultura na relação com seus pares (Corsaro, 2011). Com base nessa compreensão, podemos dizer que as crianças, enquanto brincam, constroem novos 
significados que são expressos em suas formas específicas de simbolizar o mundo, recriando novas culturas em suas relações. Isso não é diferente quando lidam com jogos digitais, pois são ferramentas cada vez mais presentes no seu cotidiano, agindo no processo de desenvolvimento infantil como campo de aprendizagem (Muller, 2014).

No contexto da Educação Infantil, a Base Nacional Comum Curricular (BNCC) aponta objetivos de aprendizagem e desenvolvimento baseados em Campos de Experiências, o que implica em mudanças significativas na organização dos contextos de aprendizagem tradicionais, incluindo práticas sociais e culturais de uma comunidade e as múltiplas linguagens simbólicas que nelas estão presentes (Brasil, 2018). Os Campos de Experiências constituem-se como forma de organização curricular adequada para a educação da criança de até 6 anos, considerando os seus direitos de aprendizagem e desenvolvimento, se organizando da seguinte forma: i) $\mathrm{O}$ eu, o outro e o nós; ii) Corpo, gestos e movimentos; iii) Traços, sons, cores e formas; iv) Escuta, fala, pensamento e imaginação; v) Espaços, tempos, quantidades, relações e transformações. Essa organização potencializa experiências de distintas naturezas, dadas a relevância e a amplitude dos desafios enfrentados pela criança em seu processo de viver, compreender o mundo e a si mesma, enfatizando noções, habilidades, atitudes e valores.

Este artigo propõe investigar trabalhos que analisam as contribuições dos jogos educacionais digitais (JED), a partir das habilidades da BNCC na organização curricular por campos de experiências, a fim de verificar por meio de revisão sistemática quais relações existem entre esse tipo de ferramenta e os campos de experiências propostos às crianças da Educação Infantil. Ele segue organizado em quatro seções, a partir desta introdução. A seção 2 discorre sobre os procedimentos metodológicos utilizados na revisão sistemática. A seção 3 apresenta os resultados e discussões acerca das questões de pesquisa elaboradas para a revisão. Por fim, a seção 4 expõe as conclusões do trabalho.

\section{Procedimentos Metodológicos}

Em termos metodológicos, este trabalho se insere em uma perspectiva de natureza bibliográfica, configurando-se como uma revisão sistemática da literatura que utiliza um protocolo que segue as diretrizes sintetizadas por Kitchenham (2004). Para isso, utiliza os mecanismos de busca com propósito de realizar um levantamento de estudos na temática dos jogos digitais e suas contribuições para as crianças da Educação Infantil.

Portanto, nas seções a seguir serão abordados o objetivo principal e a definição das questões de pesquisa (QP), o argumento de busca e a definição da base de pesquisa, os critérios de inclusão (CI) e exclusão (CE), a extração dos dados e filtragem dos resultados obtidos e, por fim, as conclusões e apontamentos observados com a pesquisa.

\subsection{Objetivo e Questões de Pesquisa}

O objetivo principal desta revisão sistemática é analisar como os JED estão contribuindo para o processo de ensino e aprendizagem das crianças da Educação Infantil a partir das habilidades e dos campos de experiências propostos pela BNCC.

Para isso, este trabalho visa responder às seguintes Questões de Pesquisa:

- QP1: Em quais níveis da Educação Infantil as crianças estão utilizando JED no espaço escolar?

- QP2: Quais JED, objetivos e habilidades estão sendo explorados na Educação Infantil?

- QP3: Como os JED estão sendo aplicados na Educação Infantil?

- QP4: Quais áreas de conhecimento estão sendo abordadas ao utilizar JED na Educação Infantil? 


\subsection{Construção do Argumento de Busca e Definição da Base de Pesquisa}

Considerando o objetivo principal e as questões de pesquisa propostas, foram destacadas as seguintes palavras-chaves para o argumento de busca: "educação infantil" AND "jogos digitais" OR "jogos educacionais".

O processo de busca de trabalhos consistiu em apenas utilizar o indexador que subsidiaria o processo de coleta de dados pelo Google Acadêmico, sem distinção entre modalidades de trabalhos (artigo, dissertação ou tese) escritos em português e publicados entre os anos de 2013 e 2019. Assim, a coleta no portal do Google Acadêmico se deu no mês de maio de 2020, com localização de 1.394 trabalhos, sendo feito em seguida um refinamento considerando alguns critérios de inclusão e exclusão de modo que pudesse obter os trabalhos mais relevantes para o objetivo e as questões de pesquisa propostos.

\subsection{Critérios de Inclusão e Exclusão}

Apesar de a pesquisa inicial ter sido realizada a partir dos argumentos de busca identificados como relevantes, nem todos os trabalhos abordavam diretamente aqueles argumentos relacionados com o objetivo desta pesquisa. Portanto, a fim de filtrar apenas os artigos que possuem realmente alguma relação com a temática escolhida, foram definidos Critérios de Inclusão (CI) e Critérios de Exclusão (CE), cuja aplicação foi feita sobre a análise do título, resumo e palavras-chaves de cada trabalho:

\section{- Critérios de Inclusão:}

- CI1: Publicações que mencionam as seguintes palavras-chaves no título: jogos digitais ou jogos educacionais, assim como Educação Infantil. Além disso, palavras que remetem ao contexto da pesquisa tais como: ensino infantil, crianças, ludicidade digital e softwares educacionais;

○ CI2: Publicações que relatam experiências com jogos digitais na Educação Infantil;

- CI3: Publicações que apresentam relação dos jogos digitais com as habilidades propostas no nível de Educação Infantil.

- Critérios de Exclusão:

○ CE1: Publicações que não fazem uso de jogos digitais;

○ CE2: Publicações em duplicidade;

○ CE3: Publicações que não se tenha acesso ao texto na íntegra.

Os trabalhos foram elencados, lidos e distribuídos de acordo com os critérios de inclusão (CI) e exclusão (CE).

\subsection{Trabalhos Selecionados}

A filtragem dos trabalhos selecionados pela aplicação do argumento de busca foi realizada em três etapas. Primeiramente, foi feito uma leitura dos títulos aplicando o critério CI1, 294 trabalhos sendo selecionados. Na segunda etapa procedeu-se a leitura dos resumos e palavras-chaves, aplicando os critérios CI2 e CI3, a seleção sendo reduzida para 90 trabalhos. Na terceira etapa foi realizada uma leitura de todos os artigos na íntegra, aplicando os critérios CE1, CE2 e CE3, restando ao final 44 trabalhos relevantes selecionados para a extração de dados.

Dentre os 46 trabalhos excluídos, foi constatado que 4 trabalhos não correspondiam ao período filtrado, 4 trabalhos não faziam uso de JED, 4 trabalhos estavam listados em duplicidade, sendo consideradas apenas as publicações mais recentes, 4 trabalhos não disponibilizavam acesso ao texto e 30 trabalhos não apresentavam relação dos jogos digitais com as habilidades do nível da Educação Infantil. 
A análise foi estruturada tendo como auxílio uma pasta de seleção no próprio Google Acadêmico. Nesta pasta foram organizados arquivos de acordo com o ano de publicação, a idade das crianças e a área de conhecimento em que o estudo foi aplicado. Posteriormente, foram examinados os trabalhos selecionados e seus eventuais resultados a fim de poder explorar como os JED estão contribuindo no processo de ensino e aprendizagem das crianças da Educação Infantil, bem como também buscar subsídios que corroboram com as questões de pesquisa já citadas. Todos os 44 trabalhos selecionados podem ser acessados a partir do quadro presente no endereço https://bit.ly/3e $48 \mathrm{fWa}$, que está ordenado alfabeticamente pelos sobrenomes dos autores e por um identificador que facilitará a análise dos artigos nas seções a seguir.

\section{Análise dos Resultados e Discussões}

Nesta seção serão apresentadas as respostas e discussões referentes às questões de pesquisa desta Revisão Sistemática. É importante desde já destacar que, apesar de haver um número significativo de trabalhos publicados envolvendo jogos digitais com contribuições para o desenvolvimento das habilidades cognitivas das crianças, poucas ainda são as investigações referentes às práticas com estas ferramentas direcionadas aos campos de experiências da Educação Infantil propostos pela BNCC, já que se trata de um documento publicado em dezembro de 2017 e que a maior parte das pesquisas realizadas até a presente data foi produzida antes da BNCC ter sido aprovada oficialmente.

\subsection{QP1: Em quais níveis da Educação Infantil as crianças estão utilizando os JED no espaço escolar?}

Ao analisar os 44 trabalhos com relação aos níveis da Educação Infantil em que as crianças estão utilizando os jogos digitais no contexto escolar, foi encontrado apenas 1 trabalho (2\%) direcionado ao nível de creche (menores de 4 anos), que está indicado pelo identificador 25 no quadro de artigos selecionados. Além disso, 24 trabalhos (55\%) estão direcionados ao nível pré-escolar (de 4 a 5 anos e 11 meses), indicados no quadro pelos identificadores 1, 3, 7, 9, 12, 13, 16, 17, 18, 19, 22, 23, 24, 29, 30, 31, 32, 34, 35, 37, 39, 40, 41 e 43. Por fim, 19 trabalhos (43\%) que estão indicados no quadro pelos identificadores $2,4,5,6,8,10,11,14,15,20,21,26,27,28,33,36,38$, 42 e 44, não fizeram nenhuma referência ao nível ou idade das crianças.

Nesse tema observa-se que ainda são poucas as publicações voltadas para crianças do nível de creche. Percebe-se que os trabalhos analisados estão mais voltados para as crianças entre 4 e 6 anos que estão em processo de alfabetização (nível pré-escolar). É possível destacar também que, dentre estes trabalhos, nenhum fez referência à BNCC.

No entanto, a escola necessita de mais preparo para adentrar ao contexto dos JED, não somente com estas crianças pequenas, mas em sua própria base curricular. Vê-se, assim, que é preciso que as pesquisas realizadas para este nível da educação formal passem a fazer uma relação direta dos JED com os campos de experiências citados pela BNCC, não deixando essa tarefa para os professores senão as escolas continuarão ficando aquém desses recursos que repercutem na aprendizagem e estão presentes em vários aspectos da vivência e da convivência humana.

Portanto, os JED devem ser estudados e bem analisados enquanto produtos educacionais direcionados para serem inseridos na metodologia dos professores, dandolhes condições para refletirem sobre novas práticas integradas aos campos de experiências propostos pela BNCC para a Educação Infantil, de forma que possibilitem dispor de mais um recurso para uma prática pedagógica significativa. 


\subsection{QP2: Quais JED, objetivos e habilidades estão sendo explorados na Educação Infantil?}

Dentre os 44 trabalhos analisados nesta revisão sistemática, foram identificados 21 trabalhos (48\%) que relatam quais jogos digitais, objetivos e habilidades estão sendo explorados com o público da Educação Infantil no âmbito escolar. Com isso, foi possível efetuar um mapeamento para a apresentação dos resultados da QP2, organizado por meio do Quadro 1, que cataloga as informações para facilitar a análise sobre a situação atual. Devido a extensão das respostas dos trabalhos analisados, foi realizada uma síntese das mesmas que permitiu ordenar o Quadro 1 de acordo com os objetivos e habilidades em comum que foram catalogados.

Os trabalhos indicados pelos identificadores 23, 39, 2, 13, 18, 29 e 34 estão voltados para as habilidades de letramento. Os trabalhos indicados pelos identificadores 30, 20 e 33 estão voltados para as habilidades das Ciências Naturais. Os trabalhos indicados pelos identificadores 35, 22, 9 e 43 estão voltados para um contexto interdisciplinar, desenvolvendo habilidades de áreas diferentes em um mesmo jogo. Os trabalhos indicados pelos identificadores 16,19 e 26 estão voltados para as habilidades de programação e pensamento computacional. Os trabalhos indicados pelos identificadores $37,21,41$ e 28 estão voltados para as habilidades matemáticas. Além disso, todos aqueles JED que dispõem página web acessível podem ser acessados a partir dos links presentes nos seus próprios nomes indicados no Quadro 1.

Os trabalhos indicados no Quadro 1 pelos identificadores 23, 39, 2, 13, 18, 29, 34, 22, 9, 37 e 28 apresentam os JED enquanto um recurso didático metodológico usado para a melhoria do processo de ensino e aprendizagem das crianças pequenas, no início do processo de alfabetização, utilizando-se dos benefícios que os jogos trazem, além de métodos de alfabetização que envolvem mais do que a repetição mecânica de exercícios.

Os trabalhos indicados pelos identificadores 9, 16, 19 e 26 trazem reflexões sobre a importância da utilização dos JED na infância a partir de uma perspectiva construtivista, que parte do entendimento de que as crianças não se limitam a reproduzir as informações do mundo dos adultos, mas atribuem novos significados a partir das observações e vivências no seu contexto social. Além de estimular o protagonismo, a criatividade, o raciocínio e o pensamento computacional, os JED propõem o desenvolvimento de habilidades cognitivas como a capacidade de resolução de problemas, o raciocínio lógico, o pensamento estratégico, a iniciativa, a tomada de decisão, permitindo assim, a participação ativa dos alunos na construção do próprio conhecimento (Madeira, 2019).

É importante destacar que as habilidades indicadas no Quadro 1, identificadas nos trabalhos analisados, estão alinhadas com as habilidades propostas pela BNCC, embora nos trabalhos não tenha sido feita essa relação. Assim, os jogos possibilitaram às crianças o desenvolvimento de habilidades relativas ao processo de apropriação de linguagens e construção de conhecimentos. Para a BNCC, as habilidades expressam as aprendizagens essenciais a serem asseguradas ao aluno nos diferentes contextos escolares (Brasil, 2018).

Por outro lado, os trabalhos não fazem nenhuma relação direta dos JED com os campos de experiências, pois ainda se apresentam de forma fragmentada e descontextualizada, não sendo direcionados para o que os campos de experiências citados pela BNCC propõem, que consiste em acolher as experiências e os saberes das crianças, promovendo situações que elas interajam mais entre si, discutam as regras, ampliem os conhecimentos, a imaginação, a criatividade, as experiências emocionais, expressivas, cognitivas, sociais e relacionais (Brasil, 2018).

As interações e as vivências direta com os jogos permitem o convívio da criança uma variedade de experimentações concretas que os campos de experiências consideram. Desse modo, se o jogo for bem planejado, contextualizado com as vivências das crianças 
por ser uma linguagem do seu interesse, é possível construir relações com os campos de experiências propostos pela BNCC.

Quadro 1. Jogos, objetivos e habilidades propostos nos trabalhos catalogados

\begin{tabular}{|c|c|c|c|c|}
\hline ID & Trabalhos & Jogos & Objetivos & Habilidades \\
\hline 23 & $\begin{array}{l}\text { Mota; } \\
\text { Alencar, } \\
2015\end{array}$ & Educaplay & \multirow[t]{2}{*}{$\begin{array}{l}\text { Reforçar conteúdos } \\
\text { sobre letramento }\end{array}$} & \multirow[t]{2}{*}{$\begin{array}{l}\text { Sequências de ações; } \\
\text { Associação; Abstração e grafia } \\
\text { das palavras }\end{array}$} \\
\hline 39 & $\begin{array}{l}\text { Silva et al., } \\
2017\end{array}$ & $\underline{\text { Adoletras }}$ & & \\
\hline 2 & $\begin{array}{l}\text { An et al., } \\
2013\end{array}$ & Digita & \multirow[t]{2}{*}{$\begin{array}{l}\text { Auxiliar o processo de } \\
\text { alfabetização }\end{array}$} & \multirow{2}{*}{$\begin{array}{l}\text { Raciocínio lógico; Grafia das } \\
\text { palavras; Linguagem oral e } \\
\text { escrita; Associação }\end{array}$} \\
\hline 13 & $\begin{array}{l}\text { Fernandes; } \\
\text { Real, } 2018\end{array}$ & $\begin{array}{l}\text { Ludo } \\
\text { Primeiros } \\
\text { Passos }\end{array}$ & & \\
\hline 18 & $\begin{array}{l}\text { Guimarães, } \\
2019\end{array}$ & $\begin{array}{l}\text { Varal de } \\
\text { Letras }\end{array}$ & \multirow[t]{2}{*}{$\begin{array}{l}\text { Promover o processo de } \\
\text { alfabetização }\end{array}$} & \multirow[t]{2}{*}{$\begin{array}{l}\text { Leitura; Escrita; Associação; } \\
\text { Atenção e concentração }\end{array}$} \\
\hline 29 & $\begin{array}{l}\text { Pinheiro; } \\
\text { Cavalcante, } \\
2019\end{array}$ & Pato Pateta & & \\
\hline 34 & $\begin{array}{l}\text { Santana; } \\
\text { Santos, } \\
2018\end{array}$ & $\begin{array}{l}\text { GCompris / } \\
\frac{\text { Brincando }}{\text { com Ariê }}\end{array}$ & $\begin{array}{l}\text { Trabalhar o raciocínio } \\
\text { lógico e estratégico }\end{array}$ & $\begin{array}{l}\text { Coordenação motora; } \\
\text { Formação de palavras; } \\
\text { Engajamento e Motivação }\end{array}$ \\
\hline 30 & $\begin{array}{l}\text { Possolli; } \\
\text { Marchiorato } \\
, 2017\end{array}$ & $\begin{array}{l}\text { Meu dia, } \\
\text { Todo dia }\end{array}$ & $\begin{array}{l}\text { Prover meios para } \\
\text { produção e construção } \\
\text { do conhecimento }\end{array}$ & $\begin{array}{l}\text { Habilidades cognitivas e } \\
\text { motoras; Operações mentais; } \\
\text { Resolução de problemas } \\
\text { Percepção espacial e visual }\end{array}$ \\
\hline 20 & $\begin{array}{l}\text { Lima et al., } \\
2014\end{array}$ & $\begin{array}{l}\text { Sid - O } \\
\text { Explorador } \\
\text { de Planetas }\end{array}$ & $\begin{array}{l}\text { Auxiliar o } \\
\text { desenvolvimento } \\
\text { intelectual }\end{array}$ & $\begin{array}{l}\text { Curiosidade; Autoconfiança; } \\
\text { Concentração e importância de } \\
\text { completar tarefas }\end{array}$ \\
\hline 33 & $\begin{array}{l}\text { SÁ et al., } \\
2019\end{array}$ & $\begin{array}{l}\text { Super } \\
\text { Higiene }\end{array}$ & $\begin{array}{l}\text { Ensinar e conscientizar } \\
\text { as crianças sobre a } \\
\text { importância dos } \\
\text { hábitos de higiene. }\end{array}$ & $\begin{array}{l}\text { Habilidades cognitivas e } \\
\text { motoras; Curiosidade; } \\
\text { Compreensão e autonomia. }\end{array}$ \\
\hline 35 & $\begin{array}{l}\text { Schmidt, } \\
2017\end{array}$ & $\begin{array}{l}\text { Formas e } \\
\text { Desenhos }\end{array}$ & $\begin{array}{l}\text { Desenvolver } \\
\text { competências da } \\
\text { linguagem artística }\end{array}$ & $\begin{array}{l}\text { Expressão motora; } \\
\text { Associações e reconhecimento } \\
\text { de formas, objetos, cores, } \\
\text { personagens e números }\end{array}$ \\
\hline 22 & $\begin{array}{l}\text { Moreira et } \\
\text { al., } 2017\end{array}$ & $\begin{array}{l}\text { Motivaedu } \\
\text { c }\end{array}$ & \multirow[t]{2}{*}{$\begin{array}{l}\text { Desenvolver as } \\
\text { competências cognitivas }\end{array}$} & \multirow{2}{*}{$\begin{array}{l}\text { Associação de figuras; } \\
\text { Distinção de objetos; Noção } \\
\text { espacial; Coordenação motora; } \\
\text { Intuição visual e sonora }\end{array}$} \\
\hline 9 & $\begin{array}{l}\text { Cardoso, } \\
2015\end{array}$ & $\begin{array}{l}\text { Memória } \\
\text { da Mônica }\end{array}$ & & \\
\hline 43 & $\begin{array}{l}\text { Yabel; } \\
\text { Medina, } \\
2013\end{array}$ & Smart Kids & $\begin{array}{l}\text { Proporcionar a melhoria } \\
\text { no desenvolvimento } \\
\text { psicomotor }\end{array}$ & $\begin{array}{l}\text { Habilidades cognitivas, visual, } \\
\text { táctil e sonora; Motricidade; } \\
\text { Construção da autonomia }\end{array}$ \\
\hline 16 & $\begin{array}{l}\text { Gomes; } \\
\text { Melo; } \\
\text { Tedesco, } \\
2016\end{array}$ & \multirow[t]{2}{*}{ Code.org / } & \multirow[t]{2}{*}{$\begin{array}{l}\text { Disseminar o } \\
\text { pensamento } \\
\text { computacional }\end{array}$} & \multirow{2}{*}{$\begin{array}{l}\text { Lógica; Reconhecimento de } \\
\text { Padrões; Pensamento } \\
\text { algorítmico; Raciocínio; } \\
\text { Síntese; Estratégias; análise de } \\
\text { erros e formulação de } \\
\text { hipóteses. }\end{array}$} \\
\hline 19 & $\begin{array}{l}\text { Kaminski; } \\
\text { Boscarioli, } \\
2019\end{array}$ & & & \\
\hline
\end{tabular}




\begin{tabular}{|c|c|c|c|c|}
\hline 26 & $\begin{array}{l}\text { Oliveira et } \\
\text { al., } 2014\end{array}$ & $\begin{array}{l}\text { GrubiBots } \\
\text { Educaciona } \\
1\end{array}$ & $\begin{array}{l}\text { Desenvolver algoritmos } \\
\text { por meio interligação de } \\
\text { blocos com instruções }\end{array}$ & $\begin{array}{l}\text { Raciocínio lógico; Algoritmos } \\
\text { e programação }\end{array}$ \\
\hline 37 & $\begin{array}{l}\text { Silva; Pires, } \\
2017\end{array}$ & $\begin{array}{l}\text { Eu sei } \\
\text { Contar }\end{array}$ & \multirow{2}{*}{$\begin{array}{l}\text { Identificar o uso de } \\
\text { números naturais em } \\
\text { situações do seu } \\
\text { cotidiano }\end{array}$} & \multirow{2}{*}{$\begin{array}{l}\text { Algoritmo e resolução de } \\
\text { problemas; Formação e } \\
\text { ordenação dos números } \\
\text { naturais positivos; Associação } \\
\text { e seriação. }\end{array}$} \\
\hline 21 & $\begin{array}{l}\text { Menezes, } \\
2018\end{array}$ & $\begin{array}{l}\underline{123} \\
\underline{\text { Desenho }}\end{array}$ & & \\
\hline 41 & Suzin, 2017 & $\begin{array}{l}\text { Space } \\
\text { bingo }\end{array}$ & $\begin{array}{l}\text { Auxiliar no ensino da } \\
\text { multiplicação }\end{array}$ & $\begin{array}{l}\text { Desenvolvimento da memória } \\
\text { e da atenção; Associação e } \\
\text { resolução de problemas. }\end{array}$ \\
\hline 28 & $\begin{array}{l}\text { Pagnussat, } \\
2017\end{array}$ & $\begin{array}{l}\frac{\text { Farm }}{\text { Heroes }} \\
\text { Super Saga } \\
\text { / Tom \& } \\
\text { Jerry }\end{array}$ & $\begin{array}{l}\text { Desenvolver alguns } \\
\text { conceitos matemáticos }\end{array}$ & $\begin{array}{l}\text { Exploração; Deslocamento; } \\
\text { Correspondência; } \\
\text { Classificação; Atenção; } \\
\text { Seriação e contagem }\end{array}$ \\
\hline
\end{tabular}

Nesse contexto, também é importante alinhar o uso dos JED às habilidades e competências da BNCC, pois não se trata de utilizá-los somente como meio ou suporte para promover aprendizagens ou despertar o interesse dos alunos, mas para que construam conhecimentos com e sobre o uso desses jogos.

\subsection{QP3: Como os JED estão sendo aplicados na Educação Infantil?}

Dentre os 44 trabalhos analisados, apenas 7 (16\%) que estão indicados pelos identificadores 13, 18, 29, 30, 34, 37 e 43, relatam metodologias de como os JED foram aplicados durante a execução das pesquisas.

Os trabalhos indicados pelos identificadores 13, 29 e 43 empregaram uma metodologia individualizada, na qual as crianças foram desafiadas apenas a realizar atividades relacionadas às dificuldades apresentadas com relação à leitura e escrita, quais sejam: 1) Apresentação da capa do jogo digital; 2) Orientações sobre as instruções do jogo; 3) Apresentação de uma canção; 4) Apresentação de canção incompleta com banco de palavras ao lado; 5) Associação da letra com uma figura; 6) Identificação de letras para completar palavras; 7) Identificação da sílaba faltante na palavra; e 8) Coloração de cena pronta utilizando as cores disponíveis.

Percebe-se que tais métodos foram organizados de forma sistematizada. No entanto, as crianças tiveram poucas oportunidades para explorar as ferramentas a fim de desenvolver outras habilidades.

Nesse contexto, é importante que as práticas com os JED estejam considerando os direitos de aprendizagem e desenvolvimento das crianças que a BNCC estabelece: conviver, brincar, participar, explorar, expressar e conhecer, de forma que cada um deles entrelace com os campos de experiências e promova o desenvolvimento integral das crianças, respeitando suas especificidades etárias e suas singularidades (Brasil, 2018).

Os trabalhos indicados pelos identificadores 18, 30, 34 e 37 empregaram uma metodologia mais ativa e colaborativa, trabalhando em pequenos grupos, realizando observações, entrevistas e conversas com os participantes que permitiu criar um ambiente de colaboração e interação entre as crianças durante a realização da atividade proposta, quais sejam: 1) Roda de conversa com as crianças sobre a temática do jogo; 2) Orientações sobre o jogo a ser utilizado; 3) Desafios para completar palavras de objetos em diferentes níveis; 4) Observação das habilidades e o entendimento das crianças sobre 
o ambiente do jogo; 5) Projeção das atividades no quadro para promover a colaboração; e 6) Aplicação de atividades em grupos.

É importante que as práticas docentes planejadas e as pesquisas realizadas busquem dialogar com o protagonismo das crianças na diversidade de suas experiências, considerando as situações de narrar, descrever, explicar, relatar, ouvir e argumentar nos momentos em que jogam com outros colegas e com os professores, ofertando assim oportunidades da criança criar, recriar, ser ouvida e considerada.

Os trabalhos indicados pelos identificadores $4,7,8,9,12,14,18,22,25,28,31$, $33,35,40,41$ e 44 apresentam em sua pesquisa reflexões a respeito da relação entre os JED, sua utilização e sua influência na aprendizagem das crianças, afirmando que essas ferramentas contribuem para ultrapassar uma formação de sujeitos reprodutores, uma vez que ao serem usados com finalidade educativa fazem um alinhamento do desenvolvimento de habilidades e competências almejadas pelo currículo escolar com a diversão e entretenimento. Além disso, os JED devem ser incluídos como um objeto de aprendizagem na constituição familiar e na escola, de forma que o professor utilize esta ferramenta como sua aliada no processo de ensino e aprendizagem.

Nestes mesmos trabalhos é discutido o papel e o desafio dos professores como mediadores entre a criança, o jogo digital e a aprendizagem, ressaltando que o uso das tecnologias digitais não é apenas um entretenimento nem algo instrumental, necessitando assim de formação e mediação crítica. A escola deve, portanto, assegurar esse direito potencializando as aprendizagens e práticas das crianças. No entanto, em nenhum momento é ressaltado como as metodologias podem ser aplicadas para esse fim, assim como também não fazem relação com a BNCC.

É importante lembrar que práticas pedagógicas propostas e organizadas para crianças da Educação Infantil precisam fazer relação com os campos de experiências propostos pela BNCC, garantindo assim que sejam desenvolvidas experiências que envolvem interações e brincadeiras, possibilitando que as crianças enquanto participantes ativas experimentem e se apropriem dos conhecimentos socialmente construídos nas práticas culturais. O currículo da Educação Infantil é concebido como um conjunto de práticas que buscam articular as experiências e os saberes das crianças com os conhecimentos que fazem parte do patrimônio cultural, artístico, ambiental, científico e tecnológico, de modo a promover o desenvolvimento integral das crianças de 0 a 5 anos de idade (Brasil, 2010).

Diante do exposto, considera-se essencial que as pesquisas devem avançar no sentido de proporcionar experiências que permitam relatar como os jogos são aplicados e quais resultados são proporcionados ao público alvo, contribuindo assim para outras práticas pedagógicas.

\subsection{QP4: Quais áreas de conhecimento estão sendo abordadas ao utilizar JED na Educação Infantil?}

Dentre os 44 trabalhos mapeados, foi analisado e identificado que algumas áreas de conhecimento foram abordadas ao utilizar os JED. Foram encontrados 7 trabalhos (16\%) direcionados a área da Língua Portuguesa, indicados pelos identificadores 2, 13 , 18, 23, 29, 34 e 39; 3 trabalhos (6\%) são direcionados à área de Ciências, indicados pelos identificadores 20, 30 e 33; 4 trabalhos (9\%) são direcionados à área do Pensamento Computacional, indicados pelos identificadores 15, 16, 19 e 26; 4 trabalhos (9\%) são direcionados à área de Matemática, indicados pelos identificadores 21, 28, 37 e 41; e 4 trabalhos $(9 \%)$ são interdisciplinares, envolvendo mais de uma área, indicados pelos identificadores $15,16,19$ e 35 . 
Diante dessa análise percebe-se que os jogos foram usados separadamente por áreas, de acordo com as dificuldades apresentadas pelas crianças, como por exemplo na área de Língua Portuguesa na qual são vistos como proposta de ajudar as crianças que apresentam dificuldades de leitura e escrita durante seu processo de alfabetização.

Os trabalhos citados como um recurso pedagógico interdisciplinar denotam que houve uma evolução considerável nos processos de escrita e/ou aprendizagens das crianças, bem como avanços nas aprendizagens de conteúdos diversos, maiores níveis de socialização, uma maior organização interna e externa e elevação da autonomia social e intelectual das crianças que apresentavam dificuldades de aprendizagem.

Porém, é importante destacar que a organização curricular da Educação Infantil está proposta a partir dos cinco campos de experiências definidos pela $\mathrm{BNCC}$, os quais são articulados entre si e que se fazem presentes nas práticas cotidianas de maneira integrada. Logo, as práticas pedagógicas não devem ser pensadas de modo isolado e fragmentado. Consequentemente, não é necessário tratar áreas específicas para trabalhar com os JED, pois estes são recursos metodológicos que podem ser propostos de forma interdisciplinar para atender as diversas formas de conhecimentos e linguagens das crianças.

Portanto, é importante garantir que estas experiências com o uso dos JED envolvam objetivos que visam a aprendizagem dos conhecimentos em diferentes campos e das diferentes linguagens em suas variadas formas de expressão e interação.

\section{Conclusões}

Este trabalho contribuiu para que, de forma sintetizada, pudéssemos conhecer algumas experiências referentes ao uso dos JED no contexto da Educação Infantil, trazendo assim reflexões pertinentes para podermos pensar e repensar acerca deste assunto. No geral, os estudos analisados destacaram que os JED vêm trazendo grandes mudanças para a educação, causando uma diversificação das formas de aprendizagem (formal, não formal, informal). Assim, a revisão sistemática permitiu aludir a importância desta ferramenta como forma de promover uma aprendizagem motivadora, tendo seu uso entendido não somente como um mero recurso didático, mas como um instrumento cultural que deve ser utilizado na prática pedagógica e que contribui para pensarmos nas crianças como seres que reinterpretam essa cultura e a, partir dela, produzem suas próprias experiências (Muller, 2014).

Portanto, é importante que professores e pesquisadores estejam cientes dessas potencialidades e dispostos a trabalhá-las de forma intencional e planejada, considerando os diferentes modos da criança se relacionar, intervir e aprender por meio deste artefato cultural, uma vez que as possibilidades de aprendizagem proporcionadas permitem a apropriação de diferentes conhecimentos e experiências, podendo atuar de forma positiva no processo de ensino e aprendizagem, constituindo-se como uma importante ferramenta para a prática pedagógica do professor e como um instrumento facilitador da aprendizagem para a criança.

Para Finco et al. (2015), a organização de um currículo por campos de experiências consiste em colocar o fazer e o agir das crianças no centro do projeto educativo. Diante desse contexto, fica clara a necessidade de começar a construir significados com as tecnologias digitais desde a Educação Infantil, os JED podendo ser reconhecidos como grandes aliados para o desenvolvimento das habilidades propostas pela BNCC neste nível de ensino. Isso deve acontecer, principalmente, em estudos e pesquisas que estejam voltados para o uso de estratégias didático-pedagógicas que favoreçam a aprendizagem das crianças, superando as práticas tradicionais de ensino e que sejam capazes de eliminar as lacunas existentes. 
Como perspectiva de trabalhos futuros decorrentes deste estudo, a partir dos resultados apontados pela revisão sistemática, inclui-se a busca por pesquisas que apresentem reflexões sobre possíveis práticas com crianças a partir do nível de creche $(0$ a 3 anos) e que dialoguem com os campos de experiências propostos pela BNCC. Assim, tais pesquisas precisam também estar voltadas às metodologias de como os JED estão sendo aplicados no contexto da Educação Infantil, o que ainda são poucos aqueles que relatam como os professores utilizam, aplicam, e que resultados apontam no sentido de trazer contribuições para outras práticas pedagógicas.

\section{Referências Bibliográficas}

BRASIL, Ministério da Educação. Base Nacional Comum Curricular. Brasil, Ministério da Educação. Brasília, DF, 2018. Disponível em: http://basenacionalcomum.mec.gov.br/abase/. Acesso em 11 maio. 2020.

BRASIL. Ministério da Educação. Secretaria de Educação Básica. Diretrizes Curriculares Nacionais para a Educação Infantil/Secretaria de Educação Básica. Brasília: MEC, SEB, 2010. Disponível em: https://ndi.ufsc.br/files/2012/02/DiretrizesCurriculares-para-a-E-I.pdf Acesso em: 12 maio. 2020.

CORSARO, W. Sociologia da infância. Porto Alegre: Artmed, 2011.

FINCO, D.; BARBOSA, M.; FARIA, A.L.G. (orgs). Campos de experiências na escola da infância: contribuições italianas para inventar um currículo de educação infantil brasileiro. Campinas, SP: Edições Leitura Crítica, 2015.

GOMES, A.; SCAICO, P.; SILVA, L.; SANOS, I.Cultura digital na escola: habilidades, experiências e novas práticas. Recife: Pipa Comunicação, 2015.

KITCHENHAM, B. Procedures for Performing Systematic Reviews. 1th. ed. Kelle: Keele University, 2004.

MADEIRA, C. A. G. Potenciais do uso de jogos digitais no contexto da educação. In: MARA, S.; CORDEIRO, S. (org.). Mídia, infância e prática pedagógica. Natal: SEDISUFRN, 2019. p.40-68. Disponível em:

https://repositorio.ufrn.br/jspui/handle/123456789/27388. Acesso em: 30 set. 2020.

MULlER, J. C. Crianças na contemporaneidade: representações e usos das tecnologias móveis na Educação Infantil. Universidade Federal de Santa Catarina (UFSC), Santa Catarina, 2014. 198p. Dissertação (Mestrado em Educação). Disponível em: https://repositorio.ufsc.br/handle/123456789/132433. Acesso em: 05 maio. 2020.

SANTANA, S. J.; SANTOS, W. O. Softwares Educacionais como Auxílio ao Processo de Alfabetização de Estudantes da Educação Infantil. In: Workshop de Informática na Escola, 24., 2018, Fortaleza. Anais. Fortaleza - CE. Disponível em: https://brie.org/pub/index.php/wie/article/view/7866/5567. Acesso em: 05 maio. 2020. 